\title{
Maximizing resource efficiency in rural prehospital emergency medical services through call frequency analysis
}

\author{
Andrew Flynn \\ Associated Colleges of the Midwest, San José, Costa Rica; apgflynn@gmail.com
}

Received 30-X-2012 Corrected 12-III-2013 Accepted 10-VI-2013

\begin{abstract}
Rural prehospital emergency medical services are often lacking when compared with their urban counterparts in terms of resources and coordinated resource use: can only employ important resources, such as paramedics, during limited shifts. This project demonstrates a method for determining the most effective use of these limited resources in a rural Red Cross ambulance service in Guápiles, Costa Rica. In this community, paramedic services are only available six days a week for twelve hours. Emergency call frequency was mapped using 20 months of traffic accident data and after establishing that traffic accident frequency was statistically dependent on the time of day, polynomial models of the data were generated. The model functions were integrated and the results were tested for accuracy. Integrals were calculated, and the results were reported to the Guápiles Red Cross committee to achieve an improved service. Methods such as this can be applied to any emergency response service.
\end{abstract}

\section{KEY WORDS}

World Health Organization (WHO), Prehospital Emergency Medical Service(s) (PEMS), Traffic Accident (TA), Téchnico de Emergencias Medicas (Paramedic), Advanced Life Support (ALS)

\section{RESUMEN}

Los servicios de emergencia médica en lugares rurales muchas veces no tienen ni los mismos recursos ni la misma organización que los servicios de emergencia en las ciudades: solo pueden emplear recursos importantes, como paramédicos, en horarios limitados. Este estudio demuestra un método para un uso más eficaz de recursos limitados en la Cruz Roja Costarricense en Guápiles, Costa Rica. En esta comunidad, los servicios paramédicos solo están disponibles seis días a la semana por doce horas. Analicé las llamadas de emergencia sobre accidentes de tránsito de 20 meses y hallé una relación estadística con la hora del día, generando modelos polinomiales. Integré las funciones del modelo y probé las predicciones para calcular su exactitud. Entregué los resultados a la Cruz Roja para lograr un uso óptimo de los recursos. Métodos como este se pueden aplicar a cualquier servicio de emergencias médicas.

\section{PALABRAS CLAVE}

Organización Mundial de la Salud (OMS), Servicios de Emergencia Médica prehospitalaria, Accidente de tránsito, Técnico de Emergencias médicas (Paramédico), Soporte vital avanzado
The worldwide societal toll of traumatic injuries is high. Every year more than 5 million are killed outright and millions more suffer injury-related disability, job loss and economic strain (Sasser et al., 2005). The short- and longterm effects of injury greatly pressure healthcare systems, businesses and governments. With current trends such as the spread of automobile use in developing countries, the World Health Organization (WHO) predicts traumatic injury frequency to rise in coming years.

Abundant research has shown that simple prehospital care, provided by emergency medical technicians or trained laypeople, is effective in minimizing both immediate effects of traumatic injury, such as death or permanent disability, and long-term injury-related medical conditions (Sasser et al., 2005). A decrease in trauma mortality in recent decades in developed countries has been largely attributed to Prehospital Emergency Medical Service(s) (PEMS) (Roudsari et al., 2007). Most of the world's population still lives without formal PEMS, but this is rapidly changing: recent international focus on the rising rate of traumatic injuries has led to a push for such services around the world.

In many places, this movement has led to the development of PEMS that employ paramedics or even physicians. 
Fewer studies contribute to an understanding of the role of Advanced Life Support (ALS) in prehospital services, and in fact the WHO recommends against implementing advanced services in resource-scarce PEMS because their benefits are not known to outweigh their costs.

The onset of the acute medical conditions and traumatic injuries that generate emergency calls are not constant throughout the week or even the day. With the rapid push for prehospital services outpacing the research necessary to most effectively implement these services regarding cost and patient care, it is of the utmost importance to enact simple measures to match services with variations in community demand.

Daily patterns have been identified in many levels of emergency medicine. A 2002 Italian study found such circadian variations in the out-of-hospital onset of medical conditions and traumatic injuries and the emergency calls that followed (Manfredini et al., 2002). A 2005 Australian study determined the circadian variation in the frequency of medical emergencies among admitted hospital patients and recommended basing resource allocation and staffing levels on the pattern (Jones et al., 2005).

Although such fluctuations in the demand for prehospital services have been identified, little is known about the continuity of such patterns in different communities. In fact, the variations that affect prehospital services are unpredictable through other established patterns. A 2002 American traffic study found that the daily frequency of traffic accidents did not follow traffic volume, and the authors suggested that rush hour not be relied upon to predict high traffic accident frequency (Brugge et al., 2002). This assertion underscores the need for site-specific emergency call frequency analysis in every community that implements PEMS.

In countries like Costa Rica the development of PEMS has favored urban centers, which are served by thoroughly equipped and trained Red Cross paramedic ambulances, heavy rescue trucks and other resources. Rural communities often have new or developing PEMS and frequently suffer from resource limitations. This trend continues regardless of research that shows PEMS use among rural populations is disproportionately high (Wang et al., 2012). The discrepancy between rural and urban services is even more evident in the planning and resource allocation of PEMS serving individual communities. Urban services utilize call frequency analysis and other tools to best match services with demand, and rural systems usually do not.

The goal of this project was to create a simple call model to measure the frequency of emergency calls with respect to the time of the day and the week in a rural region with developing PEMS. The study then aimed to apply the model to schedule limited resources, such as a paramedic, to cover the times of highest frequency. A requirement for the method was that it predict call frequency accurately despite the lower call volume experienced in rural districts, and that it be easily adaptable to other locations using only the basic call information available to rural PEMS such as time of day.

\section{METHODOLOGY}

The method was implemented in the Guápiles Red Cross district in Limón Province, Costa Rica. The Guápiles Red Cross committee consists of three basic life support ambulances, one general rescue truck and one paramedic ambulance, and in 2011 was one of two committees in the province with paid paramedic resources. The district includes the small city of Guápiles at $10^{\circ} 10^{\prime} \mathrm{N}, 83^{\circ} 46^{\prime} \mathrm{W}$ and a surrounding area of more than $400 \mathrm{~km}^{2}$, and the Red Cross committee provides emergency medical treatment, rescue services and hospital and clinic transport to the population of approximately 70000 (Caja Costarricense de Seguro Social, 2005). Such an area exemplifies the high service demand and challenging response conditions that face rural PEMS around the world. In 2011 the Guápiles Red Cross employed a paramedic only 72 hours a week, with a 12hour standard shift from 7:00 - 19:00 Monday through Saturday. The part time paramedic services at the Guápiles Red Cross exemplify a resource that must be scheduled appropriately in order to maximize efficiency. This study used Traffic Accident (TA) calls from the Guápiles Red Cross records to create the frequency model. TAs are the leading cause of traumatic death worldwide and represent a significant component of a community's emergency response needs (Sasser et al., 2005).

\section{Data Collection}

In a 20-month study period (from 08/01/2009 to 04/20/2011) the following information was collected for every TA response: day of the week, time of day, call priority level and responders' training level. This data was separated into three sets: All TAs, Weekday TAs, and Weekend TAs. TAs for each set were catalogued by initial call time in 10-minute intervals over a 24 hour period to determine call frequency throughout the day. Similar methods for analyzing circadian event frequency have been used in previous studies of hospital emergencies and the onset of medical conditions (Manfredini et al., 2002; Jones et al., 2005). 


\section{Establishing that TA frequency was dependent on time of day}

Three tests for randomness specific to time series (Runs Above and Below Median, Runs Up and Down, and BoxPierce Test) were applied to the three data sets to test if TA frequency in the data was dependent on time of day. Since the three tests are sensitive to different types of departures from random behavior, failure to pass any test suggests that the data is not random. Tests were run on Statgraphics Centurion XV version 15.1.02.

\section{Creating and Evaluating Polynomial Models}

The number of TAs in each 10-minute section was plotted versus time of day to graph traffic accident frequency. Polynomials of best fit were created and integrated to calculate the sum of TAs during the paramedic's standard 12hour shift, 7:00 to 19:00, and this sum was compared to the raw data to evaluate the model's accuracy.

\section{Identifying the Ideal Shift}

Using the polynomial models, integrals were calculated for each 12 hour shift starting every 10 minutes in a 24 hour day (a total of 144 possible shifts). The largest integral identified the shift that most effectively encompassed times with the greatest traffic accident frequency. This process was completed for the model functions for All
Days, Weekdays and Weekends in order to predict the best 12 hour paramedic shift during weekdays and weekends.

\section{RESULTS}

A total number of 676 TAs were recorded in the 20 months study period. TAs that occurred during the standard paramedic shift numbered 364 and accounted for 53,8 percent of the total. Saturday and Sunday were the two days with the highest TA frequency and Wednesday and Thursday were the two days with the lowest.

The three data sets (All TAs, Weekday TAs, and Weekend $T A s$ ) qualitatively appeared to display a relationship between time of day and TA frequency (Fig. 1). Data sets All TAs and Weekday TAs failed all three tests of randomness applied, and data set Weekend TAs failed two of three tests (Table 1).

TABLE 1

Tests for randomness in the data

\begin{tabular}{lc}
\hline Data Set & Tests Failed \\
\hline All TAs & T1, T2, T3 \\
Weekday TAs & T1, T2, T3 \\
Weekend TAs & T2, T3 \\
T1: Runs Above and Below Median & \\
T2: Runs Up and Down \\
T3: Box-Pierce Test \\
Failure of at least one test indicates non-random behavior
\end{tabular}

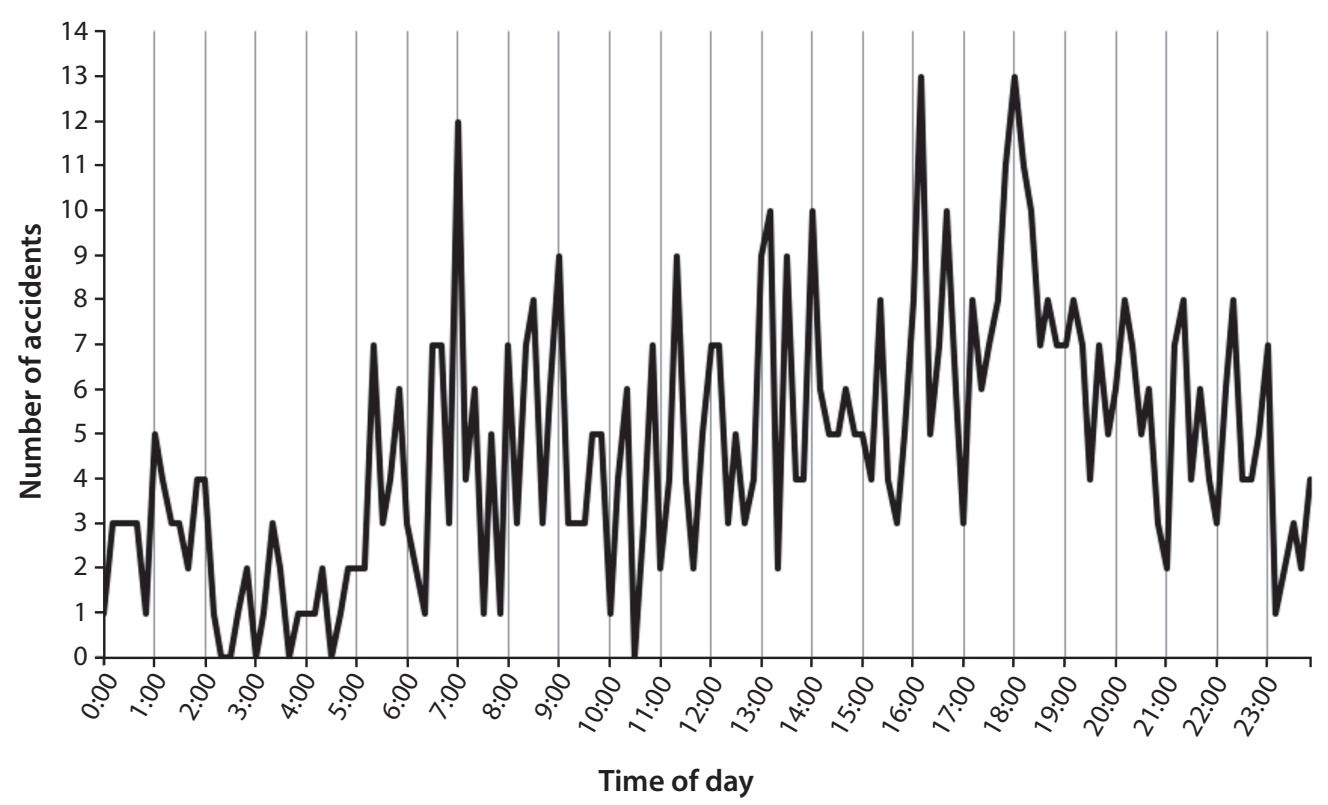

FIG. 1. Example of original data set mapped according to time of day: All TAs. 


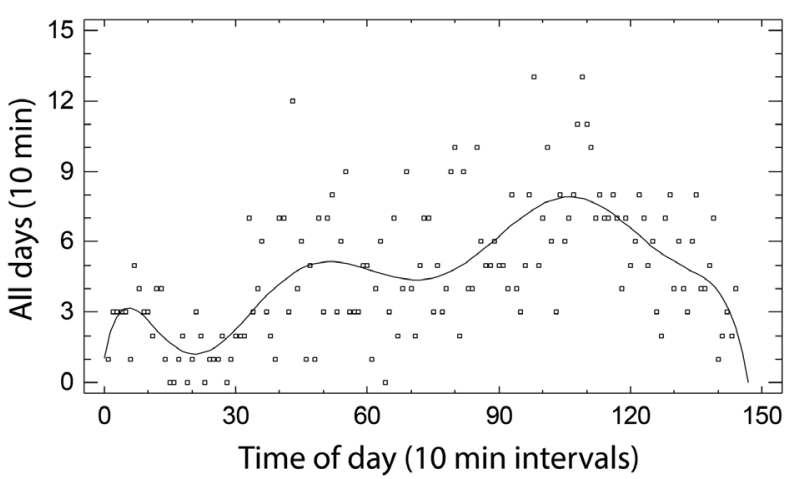

FIG. 2. Example of polynomial regression: All TAs. $f(x)$ : Number of TAs in 10-minute sections (TA frequency) $x$ : Time of Day on a 24-hour clock $(1=0: 00,2=0: 10,3=0: 20 \ldots)$

Polynomials of best fit were created and graphed for each data set to predict TA frequency (Fig. 2) and each function was integrated to model the TA sum for any given time period. For each data set, the integral was calculated for 12-hour shifts starting every 10 minutes in a 24-hour day (a total of 144 possible shifts). These values were then compared alongside one another in each data set (Fig. 3).

The predicted frequencies were checked for accuracy by comparing the predicted sum during the standard paramedic shift from the All TAs data set with the actual values from the study period. The function predicted a total of 410 TAs during the standard paramedic shift and the actual value was 419 , giving the function a percent error of 2,15 .

The 12-hour shifts with the highest predicted sums were identified for each data set. Best paramedic shifts started between 10:40 and 11:30 in the All TAs data set, started between 7:50 and 8:50 in the Weekday TAs data set, and started between 13:30 and 13:40 in the Weekend TAs data set.

All three data sets failed two or more tests for randomness where the failure of at least one test indicates nonrandom behavior. These results indicate a statistical correlation between TA frequency and time of day and suggest there are times of day with a higher need for prehospital services. All TAs and Weekday TAs failed all three tests, indicating a very strong correlation possibly due to the greater amount of data in those sets compared to Weekend TAs. Polynomial functions of best fit plotted against time of day displayed a p-value far less than 0,01 for each data set, indicating that the models were accurate representations of the data. Integration of the All TAs polynomial from the beginning to the end of the standard paramedic shift predicted a TA sum only 2,15\% different than the actual TA sum during the current shift over the study period. Such a high degree of accuracy indicates that the

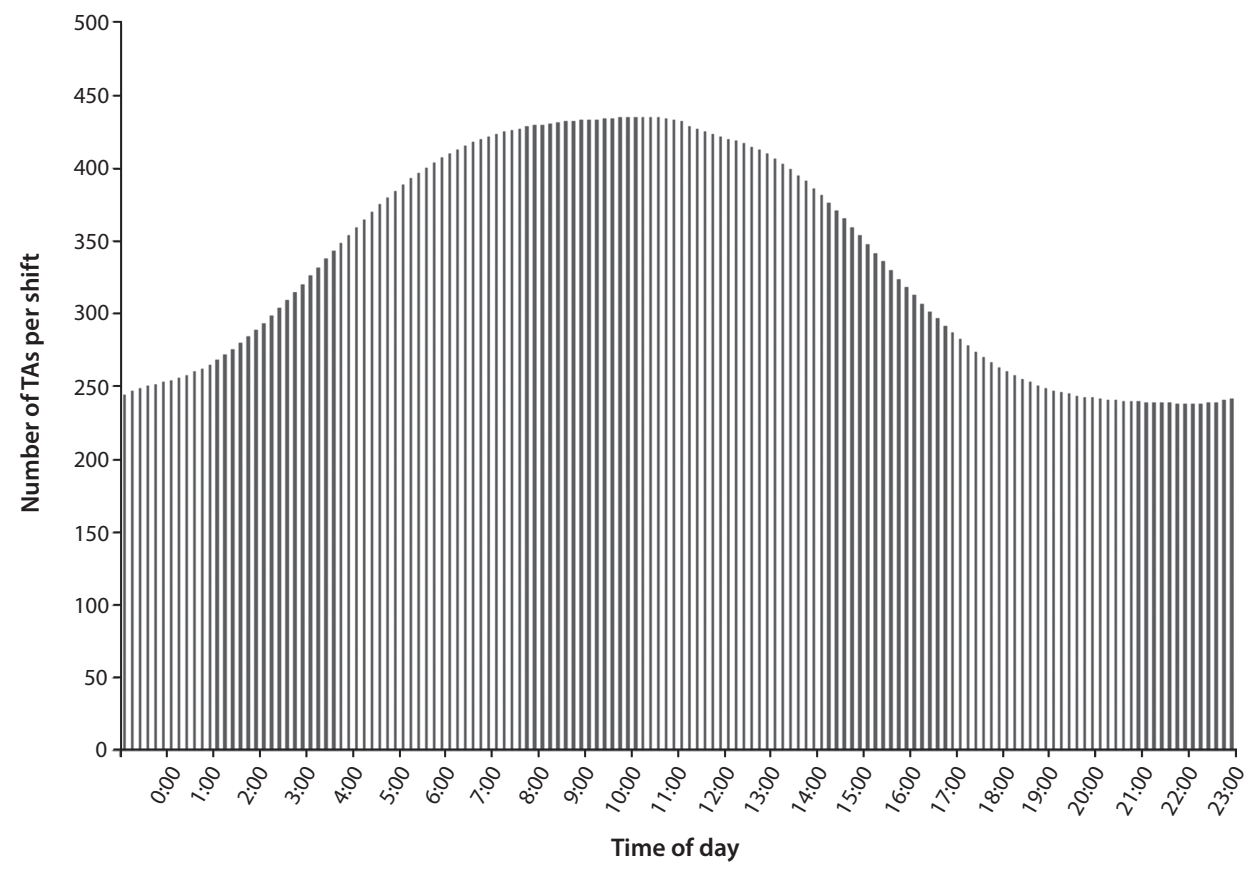

FIG. 3. Example of predicted number of TAs per 12-hr shift: All TAs. 
model functions correctly identify the relationship between TA frequency and time of day.

This method showed that at the Guápiles Red Cross Committee an ideal paramedic shift would begin on weekdays between 7:50 and 8:50 and on weekends between 13:30 and 13:40. A shift based on the All TAs data set would begin between 10:40 and 11:30. Based on TA occurrence by day, a six-day shift should run Friday through Wednesday to maximize the limited paramedic resources of the station, skipping Thursday because it is the day with least TA frequency. Basing shift scheduling on the results of this case study will maximize the number of TAs to which the paramedic can respond.

\section{DISCUSSION}

This study demonstrates circadian variations in injuries and emergency calls, which is consistent with both a 2002 Italian study and a 2005 report from Australia. The presence of such non-random behavior in studies from three different parts of the world suggests that circadian variations may be a universal characteristic of human medical emergencies. This method of emergency call modeling uses data unique to the community to generate information that can most effectively utilize resources in question (Manfredini et al.,2002; Roudsari et al., 2007). The accuracy of models in the study is not surprising; after all, the models were created from the district's own data. The improvements recommended by the study can be made without the need for additional resources or expenditure, which is not an option for a response system such as the Guápiles Red Cross. The same method can be applied to any PEMS to maximize the use of resources with limited availability, and its simplicity makes it ideal for use in resource scarce and rural PEMS (Brugge et al., 2002). It can be adapted to identify the frequency of any emergency calls that might require special resources, such as fires or certain medical events (and see Sasser et al., 2005; Wang et al., 2012).

This study recommends that new or developing PEMS utilize this method to generate a site-specific model from which limited resources can best meet community needs. Such methods will form the basis for implementing efficient
PEMS in resource scarce communities. With organized efforts the global community may be able to mitigate the effects of the predicted rise in traumatic injury in developing nations, and even extend the same decrease in traumatic mortality seen in developed nations to all communities.

\section{ACKNOWLEDGMENTS}

Special thanks to Alan Elizondo, Yolanda Castro-Duarte and the rest of the Guápiles Cruz Roja Costarricense Committee, to Christopher Vaughan, Freddy Ulate, Diana Ulate, Michael McCoy and Mario Morera.

\section{REFERENCES}

Brugge, D., Lai, Z., Hill, C., Rand, W. (2002). Traffic injury data, policy and public health. Journal of Urban Health, 79(1), 87-103.

Caja Costarricense de Seguro Social. (2005). Área de Salud Guápiles. Dirección de Compra de Servicios de Salud, San José, Costa Rica.

Jones, D., Bates, S., Warrillo, S., Opdam, H., Goldsmith, D., Gutteridge, G., \& Bellomo, R. (2005). Circadian activation of a medical emergency team in a teaching hospital. Critical Care, 9, R303-R306. doi: 10.1186/cc3537

Manfredini, R., La Cecilia, O., Boari, B., Steliu, J., Michelinidagger, V., Carlidagger, P., Zanotti, C., Bigoni, M., Gallerani, M. (2002). Circadian pattern of emergency calls: implications for ED organization. American Journal of Emergency Medicine, 20(4), 282-286.

Roudsari, B., Nathens, A., Arreola-Risa, C., Cameron, P., Civil, I., Grigoriou, G., Gruen, R. \& Rivara, F. (2007). Emergency Medical Service systems in developed and developing countries. Injury, 38(9), 1001-1013. doi: 10.1016/j. injury.2007.04.008

Sasser, S.,Varghese, M., Kellermann, A. \& Lormand, J. (2005). Prehospital Trauma Care Systems. Geneva, Switzerland: World Health Organization.

Wang, H., Mann, N., Jacobson, K., Mengtao, D., Mears, G., Smyrski, K. \& Yealy, D. (2012). National characteristics of emergency medical service responses in the United States. Prehospital emergency care, 17(1), 8-14. doi: 10.3109/10903127.2012.722178. 
